\title{
The efficacy and safety of endostar combined gemcitabine and cisplatin in the treatment of non-small cell lung cancer: a meta-analysis
}

\author{
Yixin $\mathrm{WANG}^{1}$, Lei WANG ${ }^{2}$, Jia GUO${ }^{1}$, Ziyu WANG ${ }^{3}$, Shucheng $\mathrm{HUA}^{1 *}$ (D)
}

\begin{abstract}
To determine the efficacy and safety of Endostar combined with gemcitabine and cisplatin in the treatment of NSCLC, and provide evidence-based reference for clinical drug use. Retrieved from Cochrane Library, PubMed, Embase, ClinicalTrials, CNKI, Wanfang and VIP database, randomized controlled trials (RCT) were collected. Pooled standard mean differences (SMD) and $95 \%$ confidence intervals (CI) were analyzed using R software with a random-effects model. Data from a total of 27 RCTs were included, involving 1646 patients were analyzed. Results of meta-analysis showed that response rate and clinical benefit rate of trial group were significantly higher than those of control group. There was no statistical significance in the incidence of leucopenia, thrombocytopenia and gastrointestinal reaction between 2 groups. The results showed that Endostar combined with gemcitabine and cisplatin may generally improve therapeutic efficacy of NSCLC patients, without increasing the incidence of adverse reactions.
\end{abstract}

Keywords: endostar; gemcitabine; cisplatin; non-small cell lung cancer; meta-analysis.

Practical Application: Therapeutic efficacy of Endostar combined with gemcitabine and cisplatin on NSCLC patients.

\section{Introduction}

Lung cancer is one of the most common malignant tumors in the world, and it is a serious threat to human life and health (Mao et al., 2016; Khan et al., 2020). Moreover, non-small cell lung cancer (NSCLC) accounts for approximately $80 \%$ to $85 \%$ of lung cancer (Siegel et al., 2016; Zhou et al., 2020). Because the early clinical symptoms of NSCLC are not that obvious, most patients are at the advanced stage when they seek medical consultations, and miss the opportunity of taking surgical resection (Sathiakumar et al., 2013). At present, the treatment of NSCLC is mainly chemotherapy, but the efficacy of chemotherapy is not good enough and various complications are prone (Hanna et al., 2014). However, targeted anti-tumor drugs have become one of the research hot spots in recent years. Among these targeted antitumor drugs, endostar is recognized as the best targeted drug for inhibiting tumor angiogenesis (Xu et al., 2014). Endostar is an endogenous angiogenesis inhibitor which was first isolated and purified from cultured mouse endothelial cell tumor supernatant by O'reilly MS at the end of the last century (O'Reilly et al., 1997). Endostar is able to inhibit tumor spread, prolong the survival time and improve the quality of life of cancer patients6. Researchers believe that endostar combined with chemotherapy may become an effective measure in treating tumors (Fu et al., 2009). In China, independently developed endostar has been approved for marketing by the former State Food and Drug Administration (SFDA) in 2005, combining with chemotherapy for clinical use in NSCLC. What's more, endostar is the first category of new anti-tumor drugs in biological products (Moschos et al., 2007;
Navarro-Peraza et al., 2020). Nevertheless, Studies have shown that the effectiveness, tolerability and adverse reactions of endostar combined with chemotherapy still remain controversial (Zhou et al., 2020; Sathiakumar et al., 2013; Hanna et al., 2014; Xu et al., 2014). Therefore, in this study, we systematically evaluated the efficacy and safety of Endostar combined with gemcitabine and cisplatin in the treatment of NSCLC by meta-analysis, providing evidencebased references for clinical use.

\section{Methods}

\subsection{Selection criteria}

Study type

Researchers will include all the RCTs of endostar combined gemcitabine and cisplatin in the treatment of non-small cell lung cancer. While others, such as non-RCTs, animal studies, case reports, will be excluded.

\section{Participants}

Regardless of gender, ages, nationalities and educational status, the patients with NSCLC will be included. The included participants should be diagnosed with NSCLC from cytological diagnosis, pathological diagnosis or clinical diagnosis based on the past or current diagnosis standards or guidelines of NSCLC, such as New Standard for Diagnosis and Treatment of Malignant Tumors, which is formulated by China Cancer Association. 


\subsection{Exclusion criteria}

Those who meet with the criteria given below will be excluded: 1) Jadad scale rated 0 or non-RCT literature; 2 ) duplicate publications; 3) purely descriptive research; 4) documents in the literature that cannot be extracted; 5) animal experiment.

\subsection{Interventions}

\section{Experimental interventions}

Based on routine treatment, patients in the control group were given gemcitabine and cisplatin. While patients in the trial group were given endostar on the basis of treatment in the control group.

\section{Outcome measures}

The primary outcome measure will be the efficacy of endostar combined gemcitabine and cisplatin in treating NSCLC. The secondary outcome measures will be 1) clinical benefit rate; 2) incidence of leukopenia; 3 ) incidence of thrombocytopenia; 4) incidence of gastrointestinal reactions. Efficacy criteria are divided into complete response (CR), partial response (PR), stable disease (SD), and progressive disease (PD) according to the Response Evaluation Criteria in Solid Tumors (RECIST) (Eisenhauer et al., 2009).

\subsection{Information sources}

\section{Search strategy and identification of studies}

Related literatures published from inception to October 2019, will be retrieved from the following databases: Cochrane Library, Embase, PubMed, four Chinese databases (Chinese National Knowledge Infrastructure, Chinese Science and Technology Periodicals Database, Chinese BioMedical Database and Wanfang Database). The search terms will be 'Rh-endostatin', 'Endostatin', 'Recombinant human endostatin injection', 'GP Regimen', 'Gemcitabine', 'Cisplatin', 'NSCLC', 'Non-small cell lung cancer', 'Endu, 'Chongzurenxueuguanneipiyizhisu, 'GP fangan,' 'Jixitabin', 'Shunbo', 'Feixiaoxibaofeiai. In Chinese databases, we will use the corresponding translations of these search terms to perform electronic searches. Detailed search strategy is shown as Table 1.

Other resources including references list of anteriorly published reviews and relevant conference proceedings will be searched for potential eligible studies.

The reviewers (H.S.C) will scan full articles independently. When divarication generates during the course and cannot be solved through discussion between two reviewers, the third reviewer (W.Y.X) will be consulted for arbitration.

\section{Selection of studies}

The articles with repeated results, unclear outcome data or unavailable related information, will be excluded. The reviewers (W.L.) will review titles and abstracts to select potential eligible literature and scan full articles to select the literature which can conform to the inclusion criteria, independently. A third reviewer
(W.Y.X) will solve the disagreement between two reviewers. Endnote V.X7 will be utilized for literature managements and duplication removals.

\section{Data extraction and management}

The reviewers (G.J) will independently extract data by using a data extraction sheet. The data will include the following items: general information (first author and publication year), study design, randomization methods, allocation concealment, blind method, inclusion and exclusion criteria of participants, participant's characteristics (sex, age, and duration of disease), sample size, interventions, primary and secondary outcomes, outcome assessment methods, side effects, and follow-up. Any disagreements will be discussed by the reviewers to reach consensus, and if necessary, it will be consulted with the third reviewer.

\section{Addressing missing data}

Researchers will contact with the original authors by telephone or email to request incomplete or missing data when necessary. If the information cannot be supplemented sufficiently in this way, researchers will abandon it. The potential impact of missing data will be considered in the discussion section.

\section{Risk of bias in included studies}

For assessing the risk of bias, researchers will utilize Cochrane collaboration's tool, which contains the following domains: generation of random sequence, allocation concealment, blinding method of participants, blinding method of outcome assessors, selective outcome reporting, incomplete result and other bias. In order to describe the risk of bias in each study clearly, researchers will categorize the risk into unclear, low or high (Zhu et al., 2016). The Jadad scale was used to evaluate the quality of the included studies, including the generation of random sequences ( 2 points appropriate, 1 point unclear, and 0 point inappropriate), randomized hiding (2 points appropriate, 1 point unclear, and 0 points inappropriate), blind method ( 2 points appropriate, 1 point unclear, 0 points inappropriate), withdrawal and withdrawal (1 point described, 0 points not described). 0 to 3 are regarded as low quality studies, 4 to 7 are regarded as high quality studies (Haynes et al., 2006).

\subsection{Statistical analysis}

Data synthesis and analysis

Rev Man 5.3 software will be performed to analyze the data we obtained. We will calculate standard mean difference with $95 \%$ CIs for continuous outcomes and risk ratios (RRs) with 95\% CIs for dichotomous outcomes.

For assessing the heterogeneity, a fixed effect model is used for analysis. otherwise, a random effect model is used for analysis. Sensitivity analysis is applied for assessing the stability of the results. Post-funnel plots, Begg's and Egger's tests (the latter two using Stata 12.0 software) are used for publication bias analysis. $\mathrm{P}<0.05$ is considered statistically significant. 


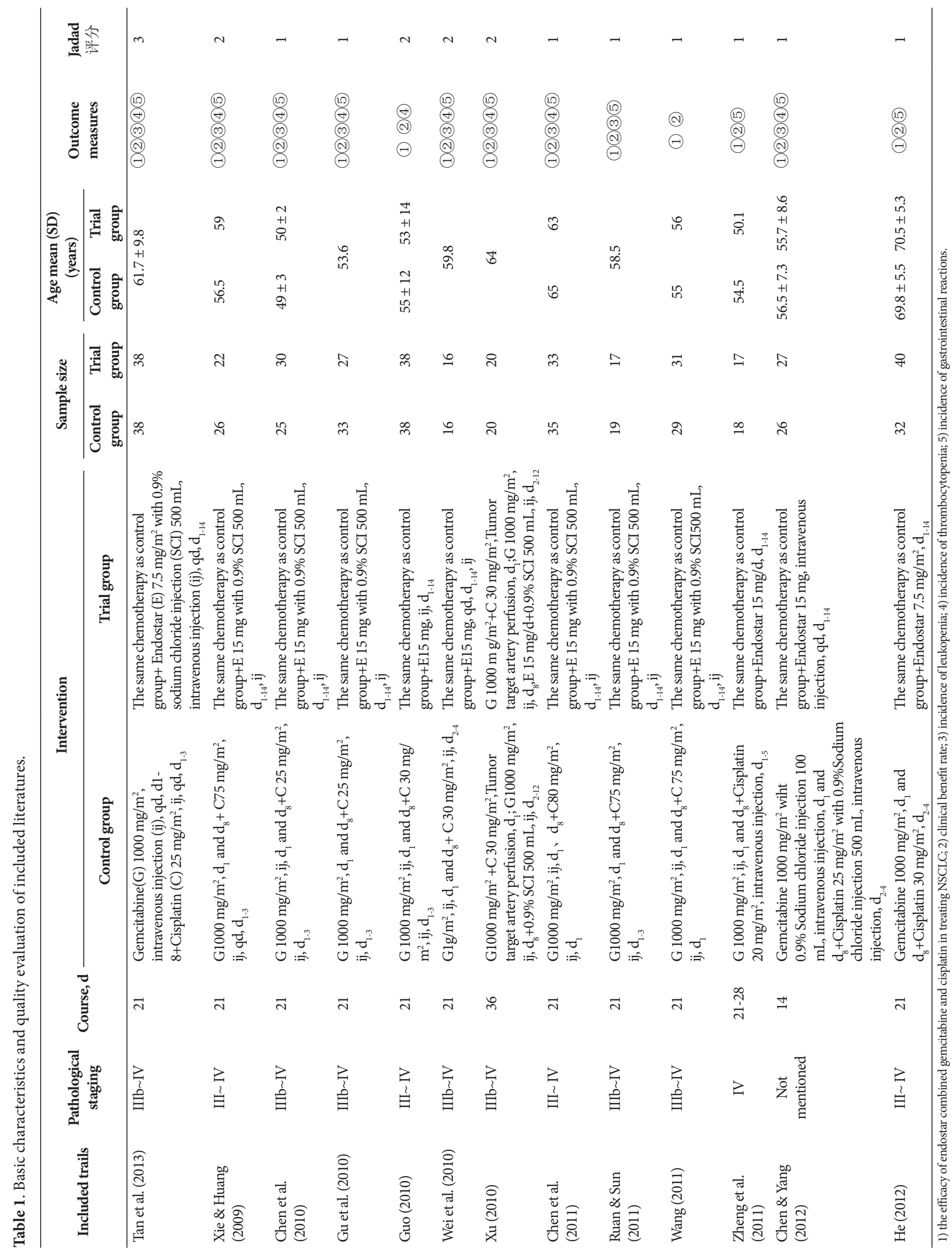




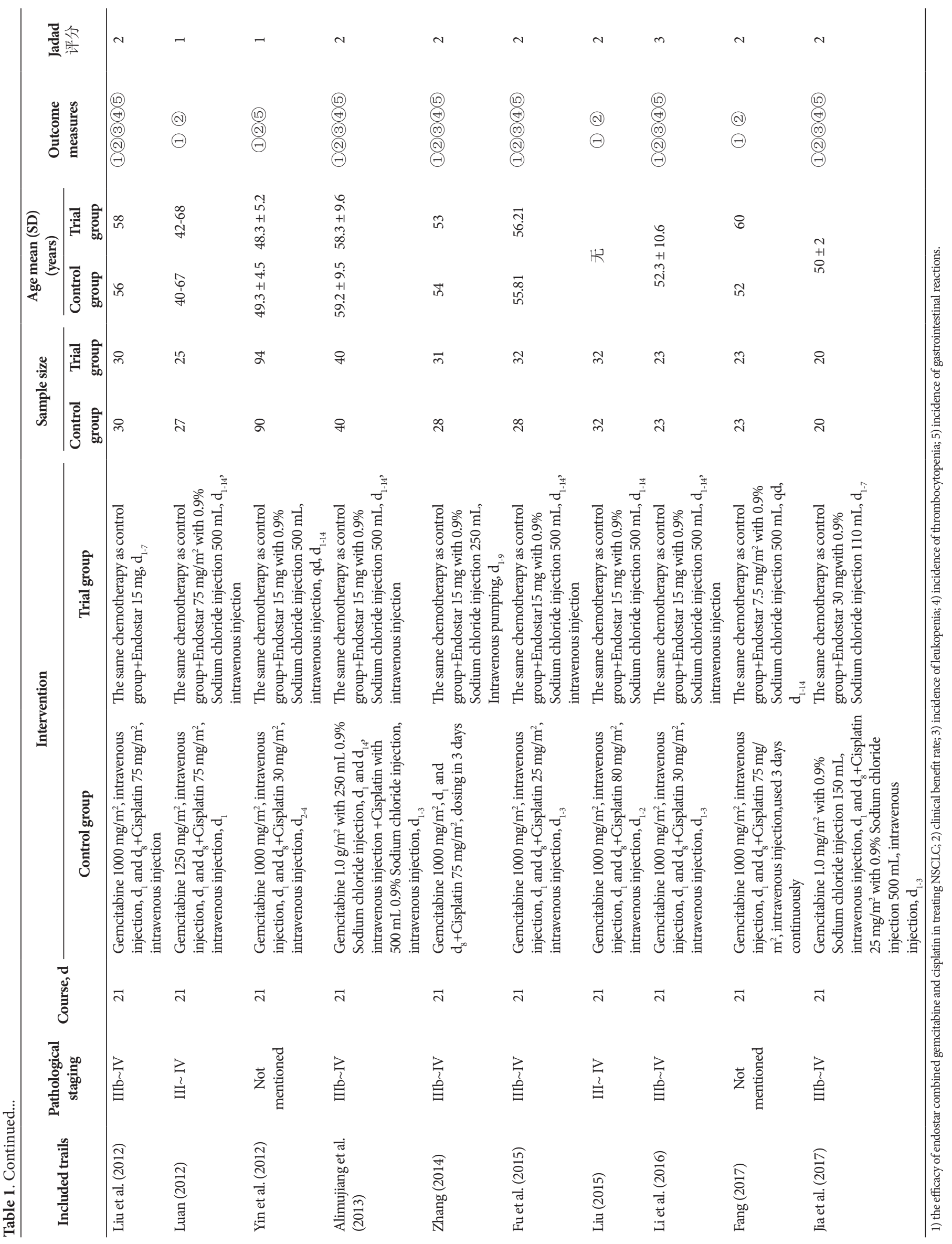




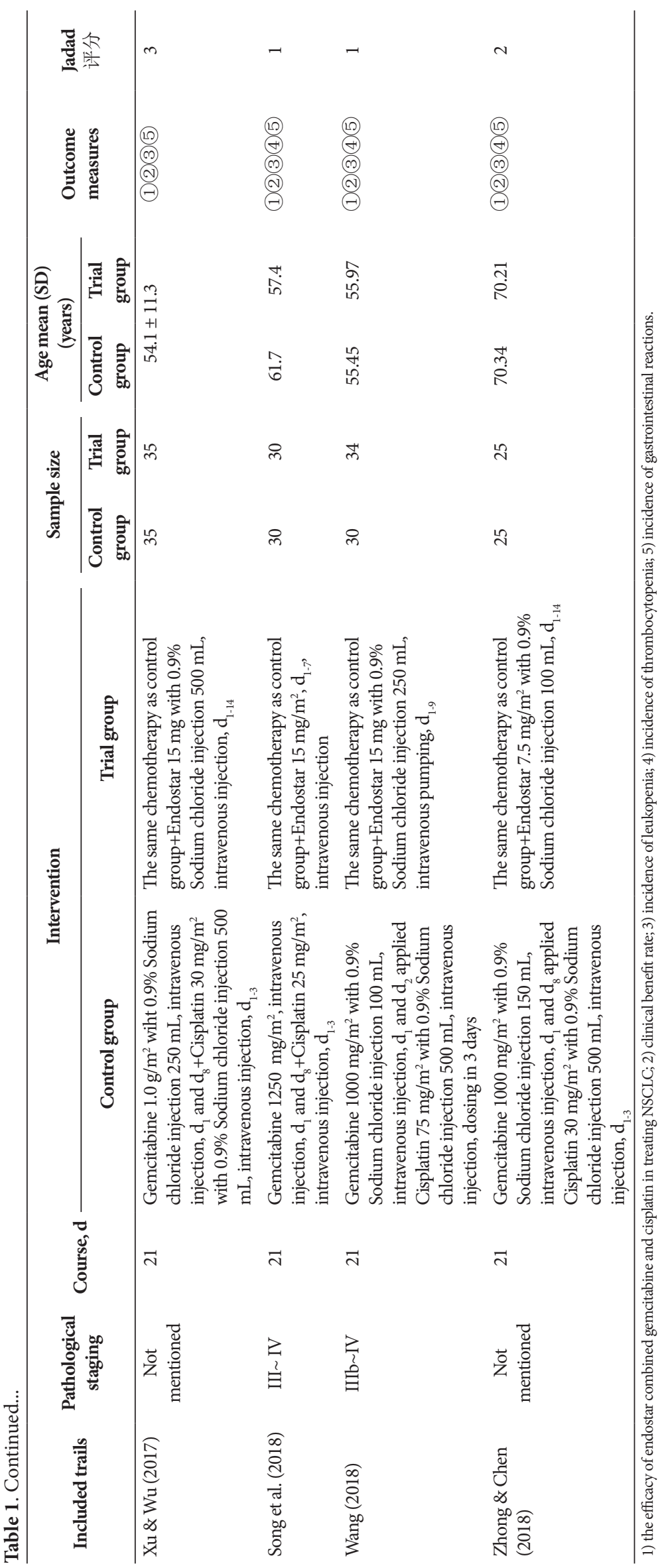




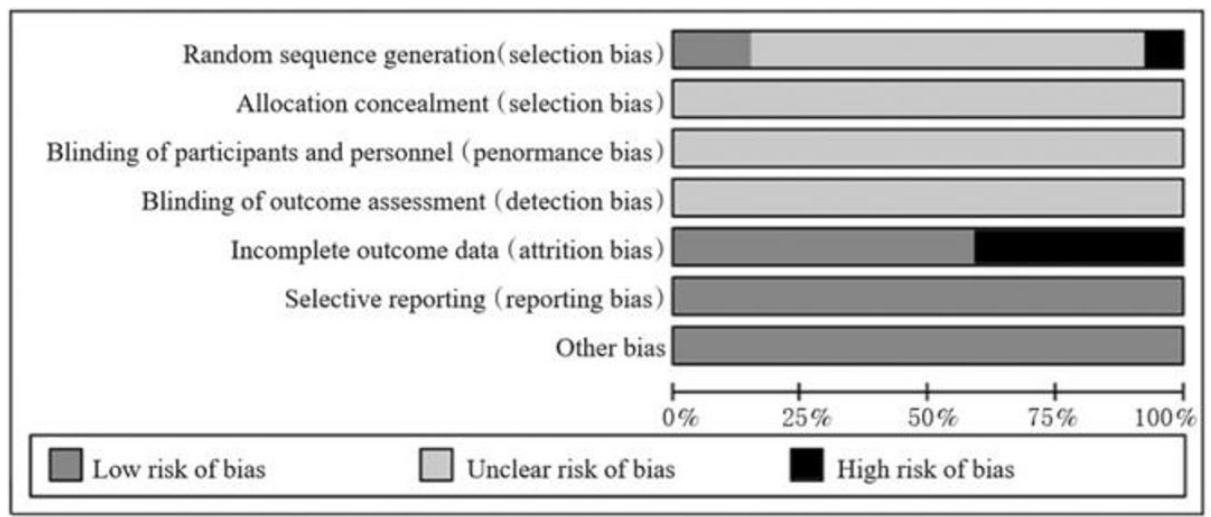

Figure 1. Bar graph of bias risk.

\section{Results}

\subsection{Description of studies}

We identified 360 potentially relevant articles, in which 317 were in Chinese and 43 were in English. After screening titles and abstracts, 81 articles were excluded owing that they were nonclinical studies, expert experience, or case reports. We reviewed the remaining 81 studies, 54 were excluded because they did not meet with our inclusion criteria. Therefore, 27 articles (Alimujiang et al., 2013; Chen et al., 2010, 2011; Chen \& Yang, 2012; Fang, 2017; Fu et al., 2015; Gu et al., 2010; Guo, 2010; He, 2012; Jia et al., 2017; Li et al., 2016; Liu et al., 2012; Liu, 2015; Luan, 2012; Ruan \& Sun, 2011; Song et al., 2018; Tan et al., 2013; Wang, 2011, 2018; Wei et al., 2010; Xie \& Huang, 2009; Xu \& Wu, 2017; Xu, 2010; Yin et al., 2012; Zhang, 2014; Zheng et al., 2011; Zhong et al., 2019) involving 1646 participants met our inclusion criteria, in which 830 participants were in the trial group and 816 participants were in the control group.

\subsection{Study characteristics}

All studies (Alimujiang et al., 2013; Chen et al., 2010, 2011; Chen \& Yang, 2012; Fang, 2017; Fu et al., 2015; Gu et al., 2010; Guo, 2010; He, 2012; Jia et al., 2017; Li et al., 2016; Liu et al., 2012; Liu, 2015; Luan, 2012; Ruan \& Sun, 2011; Song et al., 2018; Tan et al., 2013; Wang, 2011, 2018; Wei et al., 2010; Xie \& Huang, 2009; Xu \& Wu, 2017; Xu, 2010; Yin et al., 2012; Zhang, 2014; Zheng et al., 2011; Zhong et al., 2019) included are RCTs. 6 studies (Fu et al., 2015; Li et al., 2016; Song et al., 2018; Tan et al., 2013; $\mathrm{Xu} \& \mathrm{Wu}, 2017$; Zheng et al., 2011) reported random methods. 8 studies (Chen et al., 2010; Chen \& Yang, 2012; Fu et al., 2015; Gu et al., 2010; Luan, 2012; Wang, 2011, 2018; Zheng et al., 2011) results data are incomplete; all studies did not mention allocation concealment, blindness, and whether there are other sources of bias. Detailed characteristics of included studies are listed in Figures 1 and 2.

\subsection{Assessment by meta-analysis}

Efficacy assessment

Twenty-seven studies (Alimujiang et al., 2013; Chen et al., 2010, 2011; Chen \& Yang, 2012; Fang, 2017; Fu et al., 2015;

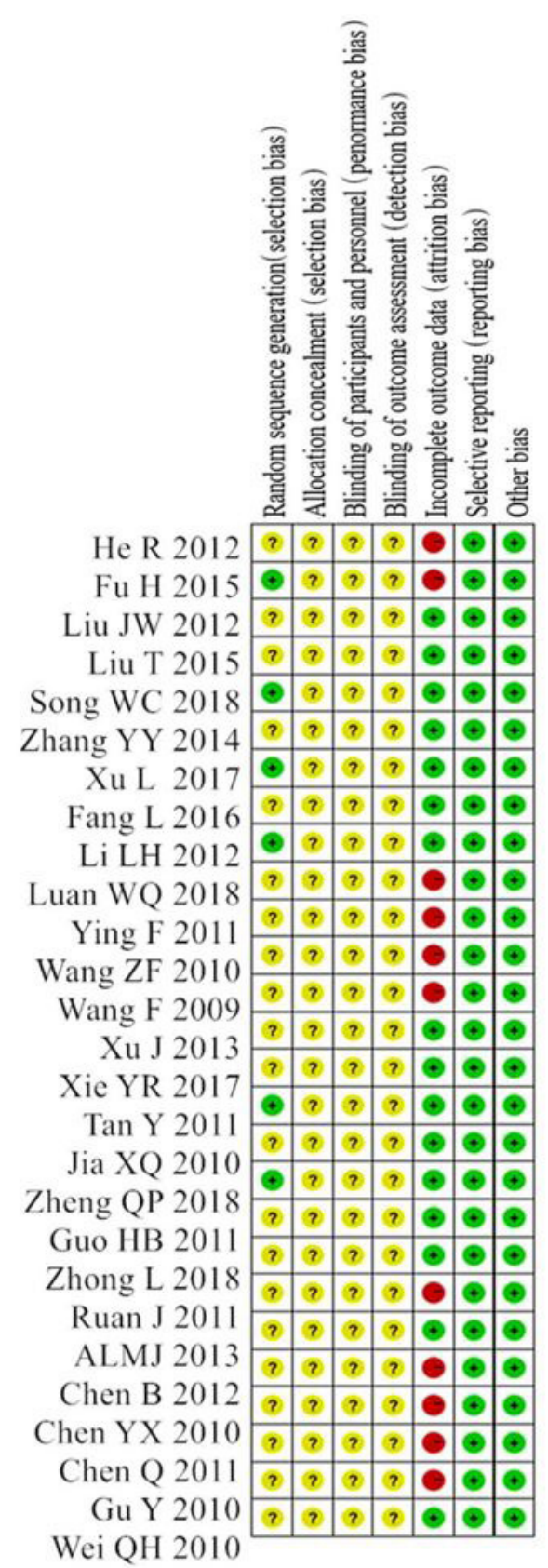

Figure 2. Risk of bias summary. 
Gu et al., 2010; Guo, 2010; He, 2012; Jia et al., 2017; Li et al., 2016; Liu et al., 2012; Liu, 2015; Luan, 2012; Ruan \& Sun, 2011; Song et al., 2018; Tan et al., 2013; Wang, 2011, 2018; Wei et al., 2010; Xie \& Huang (2009); Xu \& Wu, 2017; Xu, 2010; Yin et al., 2012; Zhang, 2014; Zheng et al., 2011; Zhong \& Chen, 2018) reported efficiency, and there was no statistical heterogeneity between the studies $(\mathrm{P}=0.99, \mathrm{I} 2=0)$. Meta-analysis was performed using a fixed-effects model. Details are showed in Figure 3. Meta analysis results showed that the efficacy of patients in the trial group is significantly higher than that in the control group, and the difference is statistically significant $[\mathrm{RR}=1.67$, 95\% CI (1.48, 1.89), P <0.000 01].

\section{Clinical benefit rate}

Twenty-seven studies (Alimujiang et al., 2013; Chen et al., 2010, 2011; Chen \& Yang, 2012; Fang, 2017; Fu et al., 2015; Gu et al., 2010; Guo, 2010; He, 2012; Jia et al., 2017; Li et al., 2016; Liu et al., 2012; Liu, 2015; Luan, 2012; Ruan \& Sun, 2011; Song et al., 2018; Tan et al., 2013; Wang, 2011, 2018; Wei et al., 2010; Xie \& Huang (2009); Xu \& Wu, 2017; Xu, 2010; Yin et al., 2012; Zhang, 2014; Zheng et al., 2011; Zhong \& Chen, 2018) reported clinical benefit rates, and there was no statistical heterogeneity between the studies $(\mathrm{P}=0.49, \mathrm{I} 2=0)$. Meta-analysis was performed using a fixed-effects model. Details are shown in Figure 4. Meta analysis results showed that the clinical benefit rate of patients in the trial group was significantly higher than that in the control group, and the difference was statistically significant $[\mathrm{RR}=1.26,95 \% \mathrm{CI}(1.20,1.33), \mathrm{P}<0.00001]$.

\section{Incidence of leukopenia}

19 studies (Alimujiang et al., 2013; Chen et al., 2010, 2011; Chen \& Yang, 2012; Fu et al., 2015; Gu et al., 2010; Jia et al., 2017; Li et al., 2016; Liu et al., 2012; Ruan \& Sun, 2011; Song et al., 2018; Tan et al., 2013; Wang, 2018; Wei et al., 2010; Xie \& Huang (2009); Xu \& Wu, 2017; Xu, 2010; Zhang, 2014; Zhong \& Chen, 2018) reported the incidence of leukopenia, and there was no statistical heterogeneity between the studies $(\mathrm{P}=1.00, \mathrm{I} 2=0)$. We applied a fixed-effects model for meta-analysis. Details are shown in Figure 5. Meta analysis results showed that there was no significant difference in the incidence of leukopenia between the two groups of patients $[\mathrm{RR}=0.98,95 \% \mathrm{CI}(0.88,1.11), \mathrm{P}=0.79]$.

\section{Incidence of thrombocytopenia}

Eighteen studies (Alimujiang et al., 2013; Chen et al., 2010, 2011; Chen \& Yang, 2012; Fu et al., 2015; Gu et al., 2010; Guo, 2010; Jia et al., 2017; Li et al., 2016; Liu et al., 2012; Song et al., 2018; Tan et al., 2013; Wang, 2018; Wei et al., 2010; Xie \& Huang (2009); Xu, 2010; Zhang, 2014; Zhong \& Chen, 2018) reported the incidence of thrombocytopenia without statistical heterogeneity among the studies $(\mathrm{P}=0.97, \mathrm{I} 2=0)$. Meta-analysis

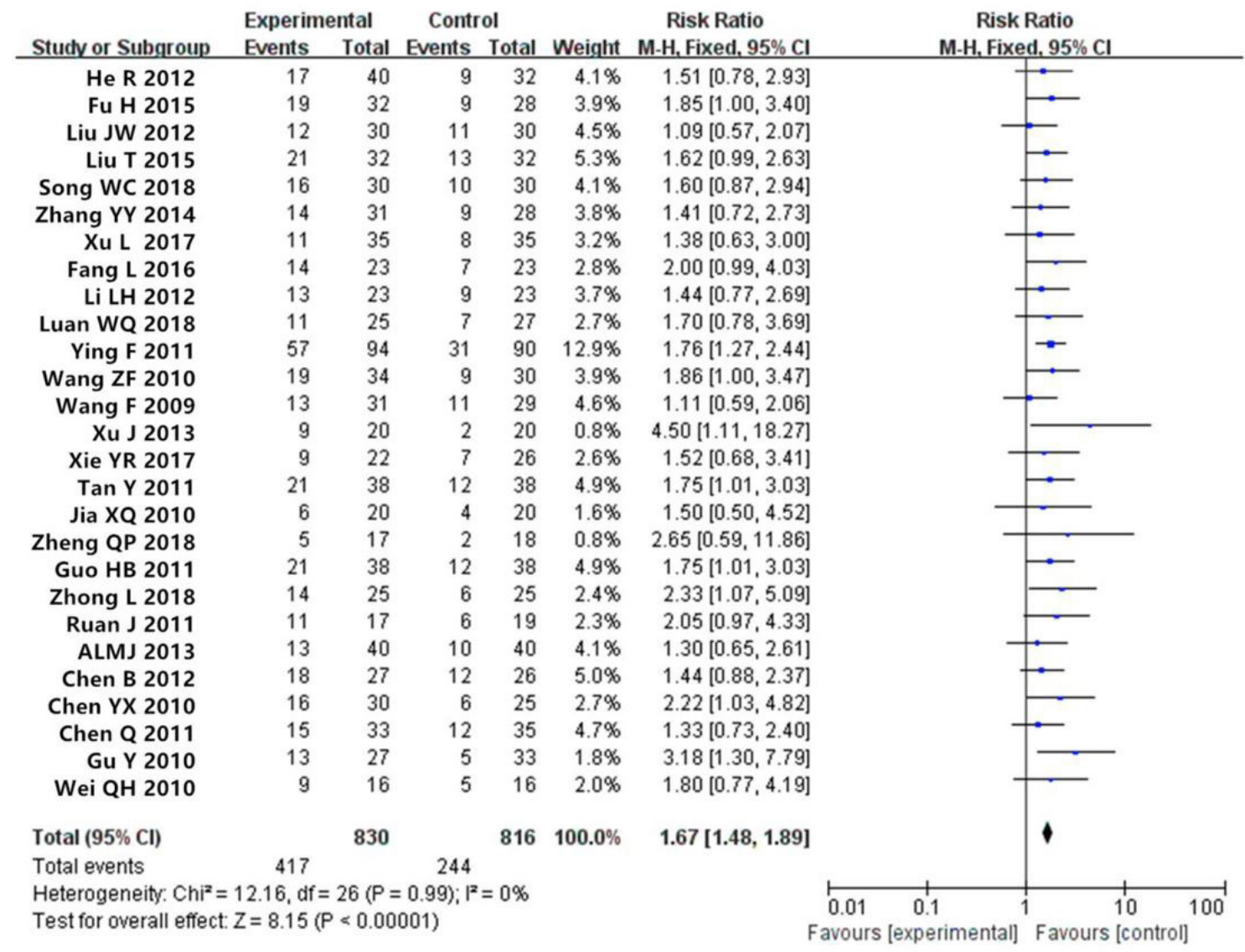

Figure 3. Forest plot of efficiency. 


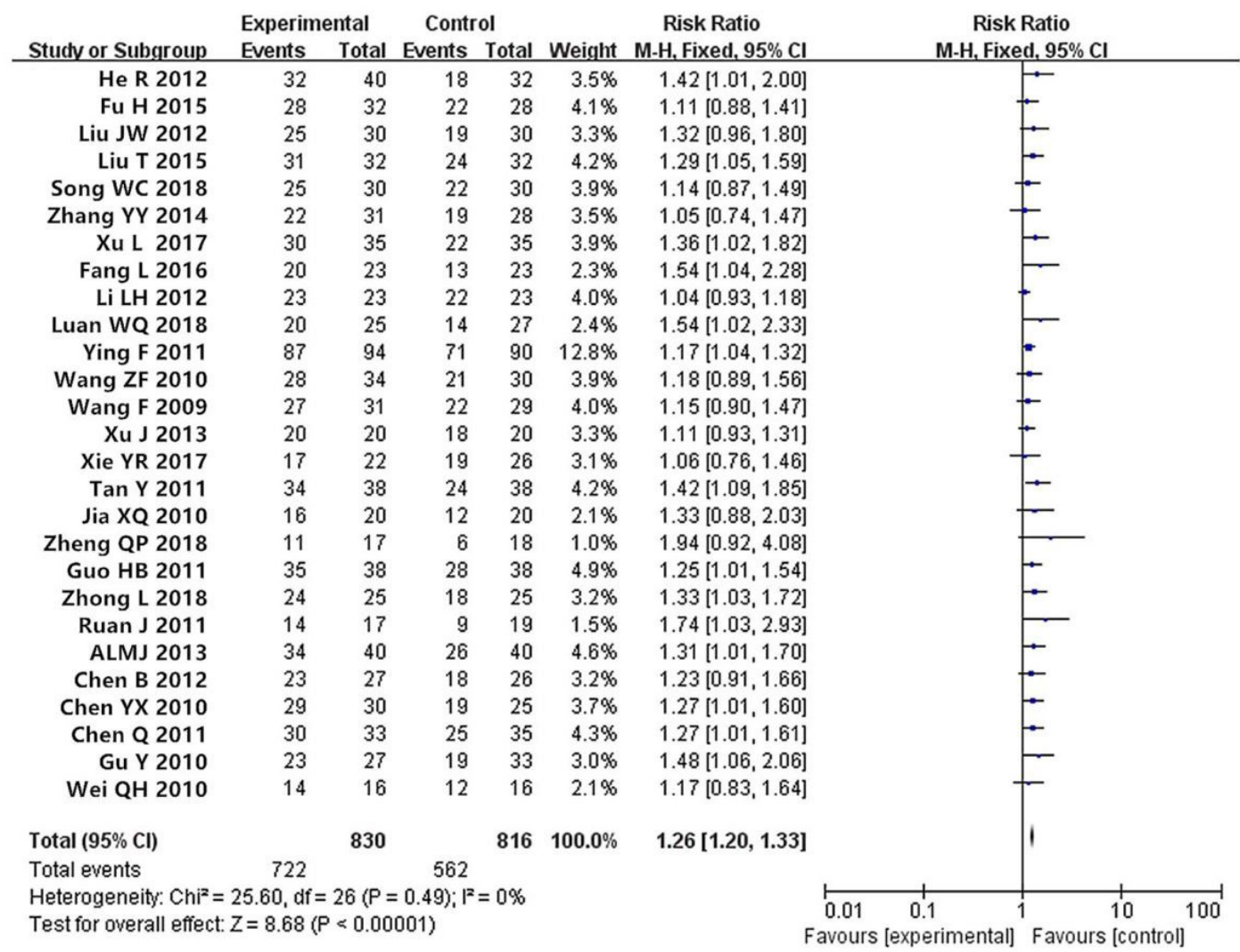

Figure 4. Forest plot of clinical benefit rate.

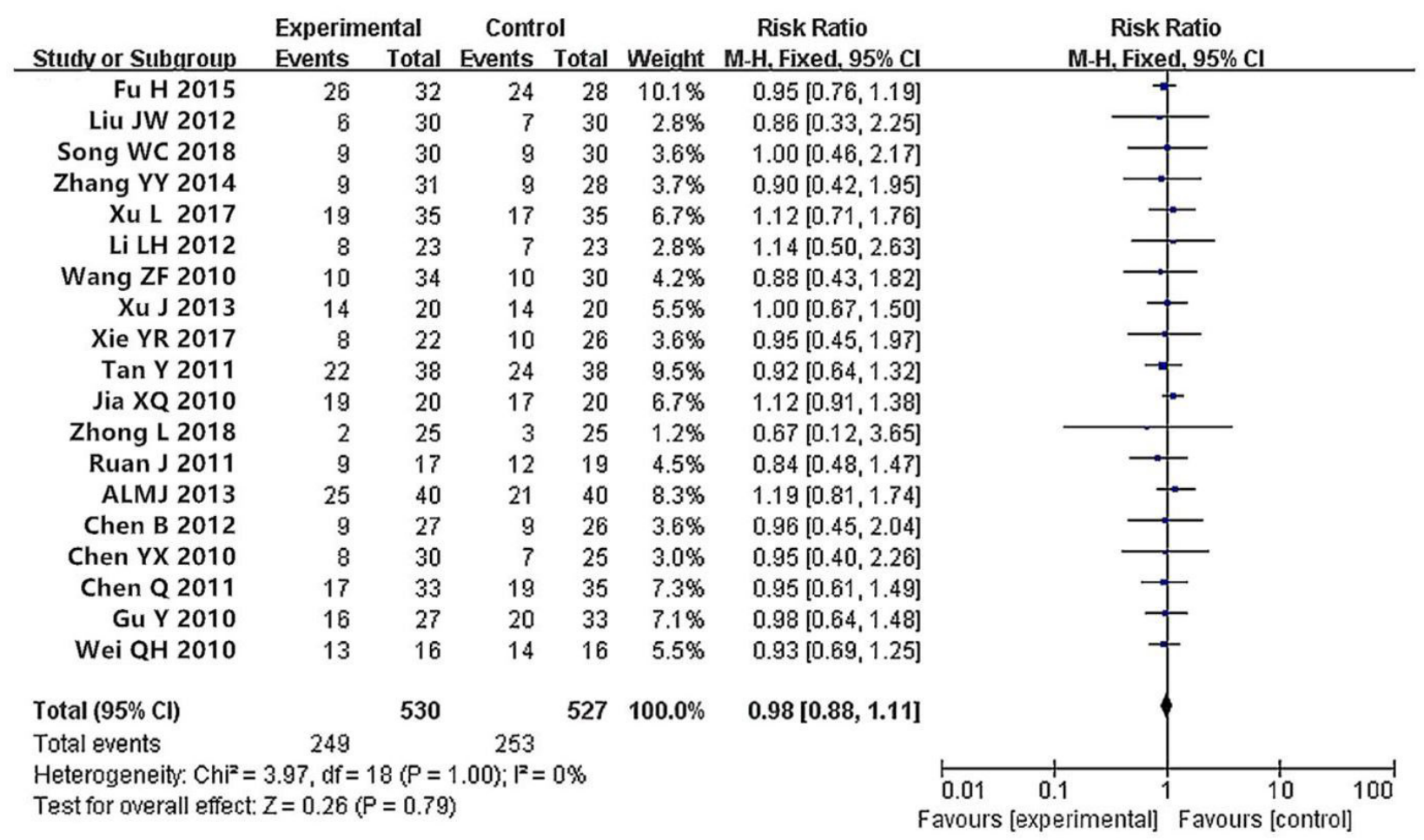

Figure 5. Forest plot of the incidence of leukopenia. 
was performed using a fixed-effect model. Details were shown in Figure 6. Meta analysis showed that there was no significant difference in the incidence of thrombocytopenia between the two groups of patients $[\mathrm{RR}=1.07,95 \% \mathrm{CI}(0.91,1.26), \mathrm{P}=0.39]$.

\section{Incidence of gastrointestinal reactions}

Twenty-two studies (Alimujiang et al., 2013; Chen et al., 2010, 2011; Chen \& Yang, 2012; Fu et al., 2015; Gu et al., 2010;
He, 2012; Jia et al., 2017; Li et al., 2016; Liu et al., 2012; Ruan \& Sun, 2011; Song et al., 2018; Tan et al., 2013; Wang, 2018; Wei et al., 2010; Xie \& Huang (2009); Xu \& Wu, 2017; Xu, 2010; Yin et al., 2012; Zhang, 2014; Zheng et al., 2011; Zhong \& Chen, 2018) reported the incidence of gastrointestinal reactions, with no statistical heterogeneity between the studies $(\mathrm{P}=1.00, \mathrm{I} 2=0)$. Meta-analysis was performed using a fixed-effects model. Details were shown in Figure 7. Meta analysis showed that there was no significant difference in the incidence of gastrointestinal

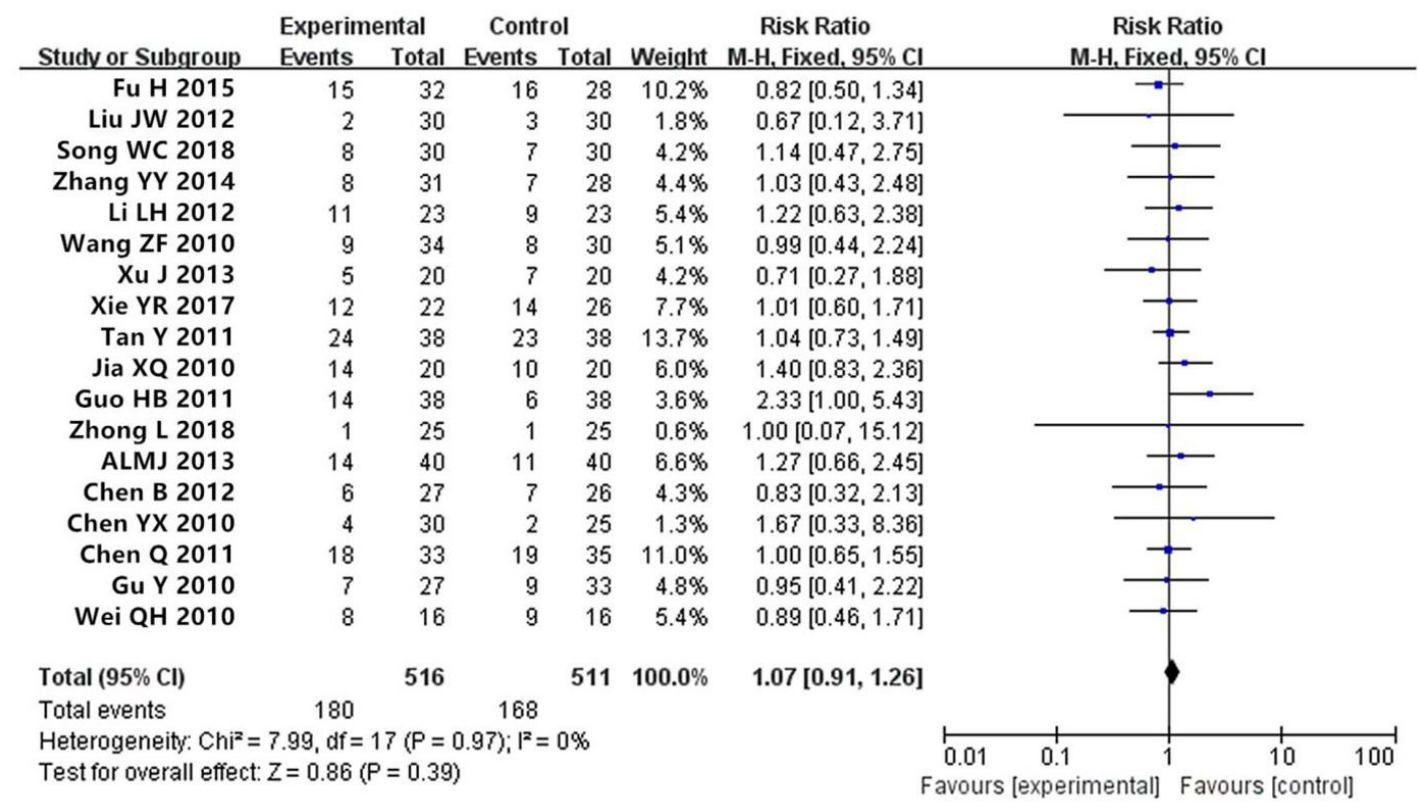

Figure 6. Forest plot of the incidence of thrombocytopenia.

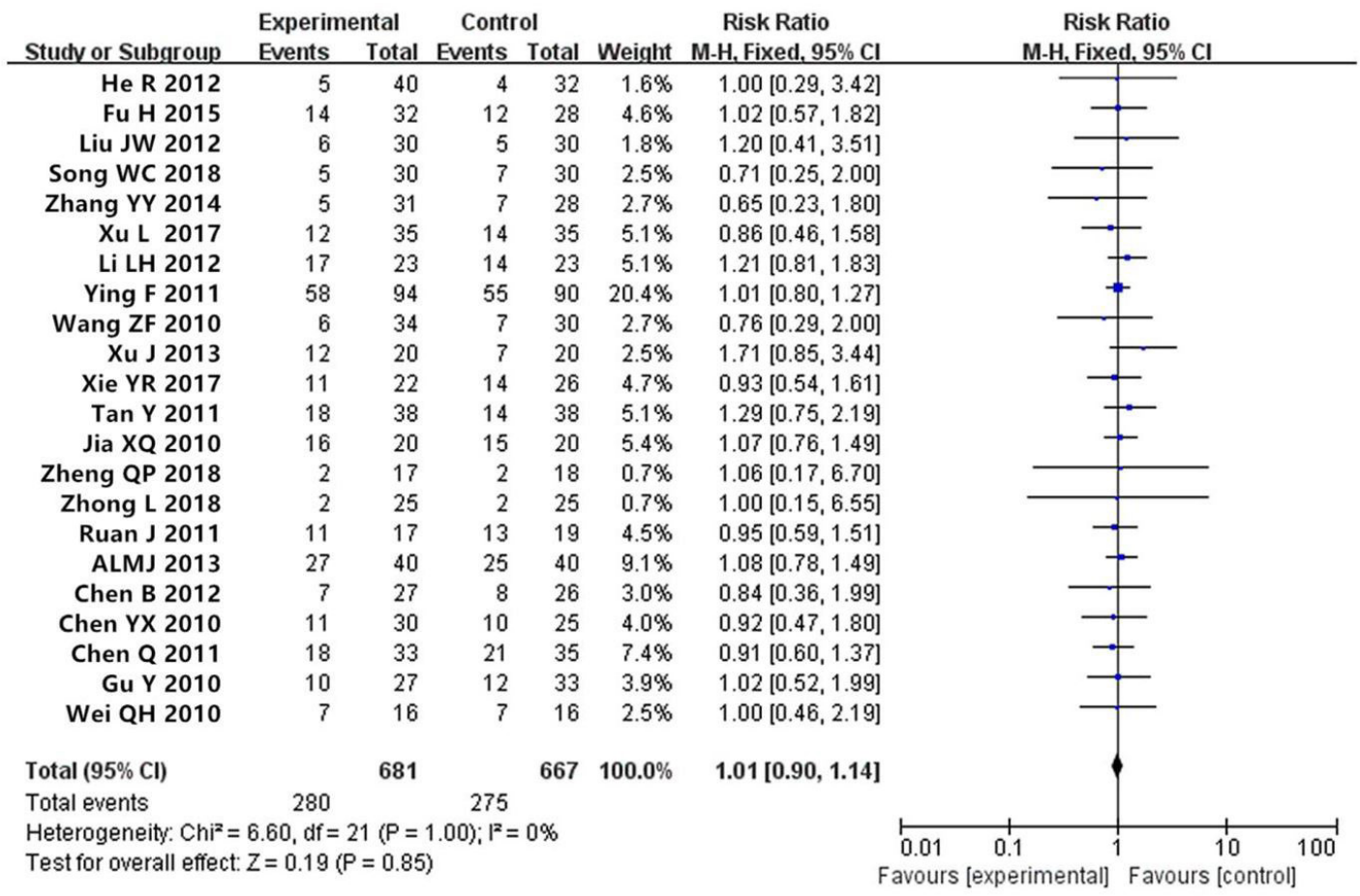

Figure 7. Forest plot of the incidence of gastrointestinal reactions. 
reactions between the two groups of patients $[R R=1.01,95 \%$ CI $(0.90,1.14), \mathrm{P}=0.85]$.

\section{Influence analysis}

We conducted the influence analysis for the included studies of efficacy. No single study affected the overall result by influence analysis (see Table 2).

\section{Publication bias}

To evaluate publication bias, we conducted the funnel plot for the included studies of efficacy (see Figures 8 to 10). Owing to insufficient details of other outcomes, we did not conduct the funnel plot. The asymmetrical figure reflected that potential publication bias might have an influence on results of metaanalysis. And no publication bias was detected by Begg's and Egger's test. (Pvalue: 0.084 and 0.135, resp.) (see Figure 9 and 10).

\section{Discussion}

Platinum drugs are cell cycle non-specific anti-tumor drugs. Its anti-cancer mechanism is that after the drug enters tumor cells, it can combine with the DNA of the tumor cells to form a Pt-DNA adduct, which then mediates tumor cell necrosis or apoptosis (Wang \& Lippard, 2005; Tao et al., 2019). Cisplatin is the first-generation platinum-based anti-tumor drug (Aixue et al., 2018). It has a broad anticancer spectrum and ideal effect, and is the first-line drug for several solid tumors (Ferry et al., 2017). Gemcitabine is not only a cytidine derivative, but also a cyclespecific anti-tumor drug. Its metabolites in the body can bind to DNA and act in the G1/S phase of the cell cycle, blocking the synthesis and repair of tumor cells' DNA (Stukov et al., 2020). Gemcitabine combined with Cisplatin is currently the firstline treatment for the clinical use of NSCLC (Holmsten et al., 2020). However, some studies have suggested that the efficacy of gemcitabine combined with cisplatin is limited, and some patients showed no significant improvement after treatment (Scagliotti et al., 2002). This suggested that the chemotherapy effect of gemcitabine and cisplatin in treating NSCLC may have reached to a bottleneck (Wu et al., 2014). Therefore, there is an urgent need to find a new treatment to control the progress of tumors.

Endostar is an anti-tumor drug with anti-angiogenic activity, which can inhibit the synthesis and proliferation of vascular endothelial cells, and play an inhibitory role in all aspects of tumor angiogenesis (Ge et al., 2011). Studies have found that nucleolar protein on the surface of cell membranes are receptors of Endostar. The drug can inhibit the growth of new blood vessels and tumors by inhibiting the phosphorylation of nucleolar protein (Shi et al., 2007). It has been reported that Endostar

Table 2. The results of sensitivity analysis.

\begin{tabular}{|c|c|c|c|c|}
\hline Excluded trails & \multicolumn{2}{|c|}{ Heterogeneity } & $95 \% \mathrm{CI}$ & $P$ \\
\hline Tan et al. (2013) & $P=0.99$ & $\mathrm{I}^{2}=0$ & $1.67(1.47,1.89)$ & $P<0.00001$ \\
\hline Xie \& Huang (2009) & $P=0.99$ & $\mathrm{I}^{2}=0$ & $1.68(1.48,1.90)$ & $P<0.00001$ \\
\hline Chen et al. (2010) & $P=0.99$ & $\mathrm{I}^{2}=0$ & $1.66(1.46,1.88)$ & $P<0.00001$ \\
\hline Gu et al. (2010) & $P=1.00$ & $\mathrm{I}^{2}=0$ & $1.65(1.45,1.86)$ & $P<0.00001$ \\
\hline Guo (2010) & $P=0.99$ & $\mathrm{I}^{2}=0$ & $1.67(1.47,1.90)$ & $P<0.00001$ \\
\hline Wei et al. (2010) & $P=0.99$ & $\mathrm{I}^{2}=0$ & $1.67(1.47,1.89)$ & $P<0.00001$ \\
\hline $\mathrm{Xu}(2010)$ & $P=1.00$ & $\mathrm{I}^{2}=0$ & $1.65(1.46,1.87)$ & $P<0.00001$ \\
\hline Chen et al. (2011) & $P=0.99$ & $\mathrm{I}^{2}=0$ & $1.69(1.49,1.92)$ & $P<0.00001$ \\
\hline Ruan \& Sun (2011) & $P=0.99$ & $\mathrm{I}^{2}=0$ & $1.66(1.47,1.89)$ & $P<0.00001$ \\
\hline Wang (2011) & $P=1.00$ & $\mathrm{I}^{2}=0$ & $1.70(1.50,1.93)$ & $P<0.00001$ \\
\hline Zheng et al. (2011) & $P=0.99$ & $\mathrm{I}^{2}=0$ & $1.67(1.47,1.89)$ & $P<0.00001$ \\
\hline Chen \& Yang (2012) & $P=0.99$ & $\mathrm{I}^{2}=0$ & $1.69(1.48,1.91)$ & $P<0.00001$ \\
\hline $\mathrm{He}(2012)$ & $P=0.99$ & $\mathrm{I}^{2}=0$ & $1.68(1.48,1.91)$ & $P<0.00001$ \\
\hline Liu et al. (2012) & $P=1.00$ & $\mathrm{I}^{2}=0$ & $1.70(1.50,1.93)$ & $P<0.00001$ \\
\hline Luan (2012) & $P=0.99$ & $\mathrm{I}^{2}=0$ & $1.67(1.48,1.90)$ & $P<0.00001$ \\
\hline Yin et al. (2012) & $P=0.99$ & $\mathrm{I}^{2}=0$ & $1.66(1.45,1.90)$ & $P<0.00001$ \\
\hline Alimujiang et al. (2013) & $P=0.99$ & $\mathrm{I}^{2}=0$ & $1.69(1.49,1.92)$ & $P<0.00001$ \\
\hline Zhang (2014) & $P=0.99$ & $\mathrm{I}^{2}=0$ & $1.68(1.48,1.91)$ & $P<0.00001$ \\
\hline Fu et al. (2015) & $P=0.99$ & $\mathrm{I}^{2}=0$ & $1.67(1.47,1.89)$ & $P<0.00001$ \\
\hline Liu (2015) & $P=0.99$ & $\mathrm{I}^{2}=0$ & $1.68(1.48,1.90)$ & $P<0.00001$ \\
\hline Li et al. (2016) & $P=0.99$ & $\mathrm{I}^{2}=0$ & $1.68(1.48,1.91)$ & $P<0.00001$ \\
\hline Fang (2017) & $P=0.99$ & $\mathrm{I}^{2}=0$ & $1.66(1.47,1.89)$ & $P<0.00001$ \\
\hline Jia et al. (2017) & $P=0.99$ & $\mathrm{I}^{2}=0$ & $1.68(1.48,1.90)$ & $P<0.00001$ \\
\hline $\mathrm{Xu} \& \mathrm{Wu}(2017)$ & $P=0.99$ & $\mathrm{I}^{2}=0$ & $1.68(1.48,1.91)$ & $P<0.00001$ \\
\hline Song et al. (2018) & $P=0.99$ & $\mathrm{I}^{2}=0$ & $1.68(1.48,1.90)$ & $P<0.00001$ \\
\hline Wang (2018) & $P=0.99$ & $\mathrm{I}^{2}=0$ & $1.67(1.47,1.89)$ & $P<0.00001$ \\
\hline Zhong \& Chen (2018) & $P=0.99$ & $\mathrm{I}^{2}=0$ & $1.66(1.46,1.88)$ & $P<0.00001$ \\
\hline
\end{tabular}

The $95 \%$ confidence interval (CI) is the probability that the population parameters are in this range, which is about $95 \%$. 


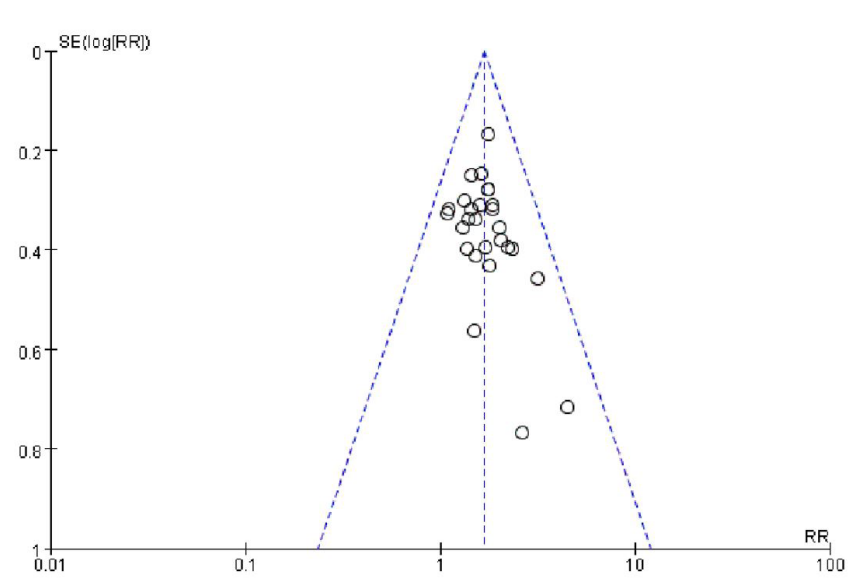

Figure 8. Funnel plot of efficiency.

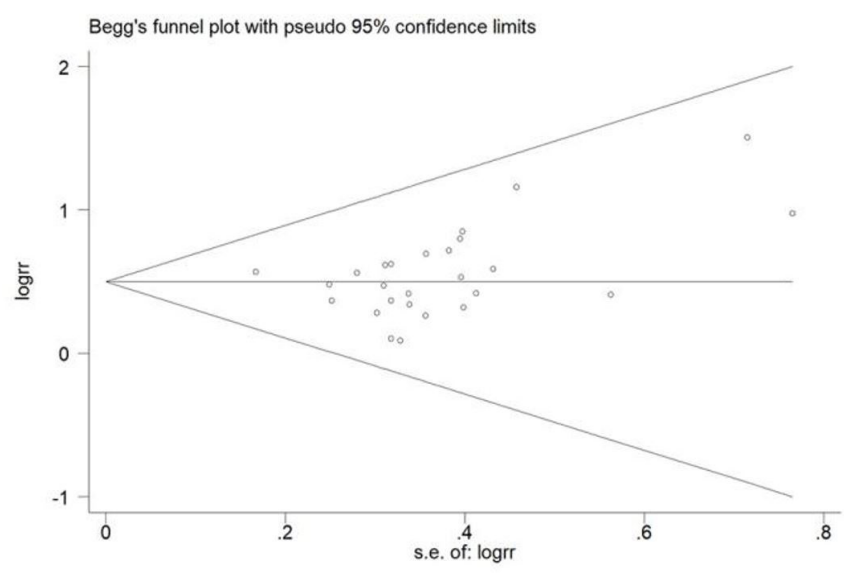

Figure 9. Begg analysis plot.

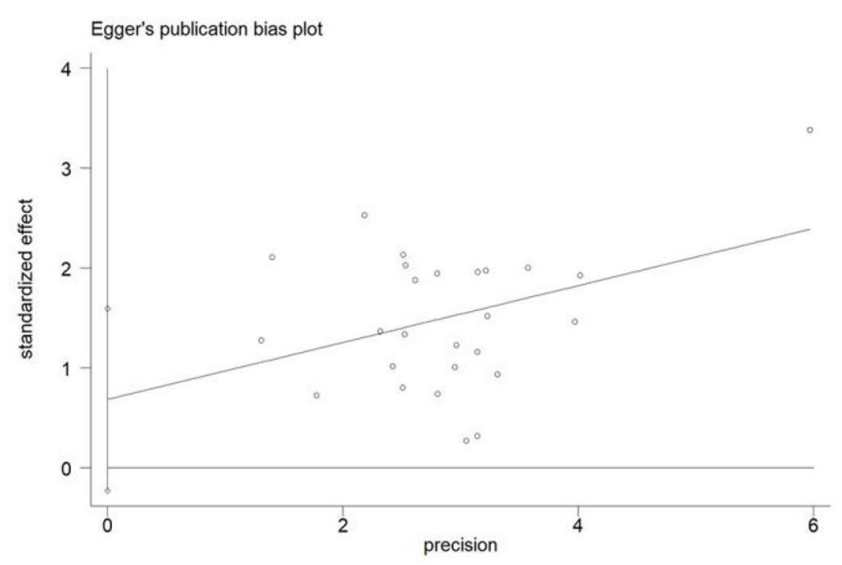

Figure 10. Egger analysis plot.

combined chemotherapy can work together to kill tumor cells and improve the efficacy in different ways (Xie \& Huang (2009).

According to this study, the results showed that the efficacy and clinical benefit rate of patients in the trial group are significantly higher than those in the control group. These results suggested that Endostar combined with gemcitabine and cisplatin can improve the efficacy in treating NSCLC. There was no significant difference in the incidence of leukopenia, thrombocytopenia, and gastrointestinal reactions in the two groups of patients. It meant that Endostar combined with gemcitabine and cisplatin will not increase the incidence of adverse reactions. What's more, inverted funnel plots, Begg's and Egger's tests all indicated that no publication bias was found in this study. However, there were stiil some limitations in this study: 1) The documents retrieved were those included in each database. Unpublished documents had not been search; 2) The included literatures are mainly Chinese literatures; the results may not reflect the whole world conditions; 3 ) None of the included literature evaluated patients' quality of life. Therefore, the conclusions of this study need to be further confirmed by high-quality, multi-center RCT. In summary, Endostar combined with gemcitabine and cisplatin can improve the efficacy of advanced NSCLC without increasing the incidence of side effects.

\section{References}

Aixue, L., Ruinian, Z., Fan, Y., Li, H., Lingyan, Z., \& Jiren, Z. (2018). Effects of curcumin on growth of human cervical cancer xenograft in nude mice and underlying mechanism. Food Science and Technology, 38(1), 106-111.

Alimujiang, S., Zhang, T., Patiguli, A., \& Liu, L. (2013). Clinical analysis of recombinant human endostatin combined with gemcitabine and cisplatin therapy in advanced non-small cell lung cancer. Shandong Daxue Xuebao. Yixue Ban, 51(3), 95-98.

Chen, B., \& Yang, W. B. (2012). Observation of curative effect of recombinant human endostatin combined with GP regimen on non-small cell lung cancer. Journal of Clinical Pulmonary Medicine, 17(5), 869-870.

Chen, Q., Xie, Q., \& Shi, Q. (2011). Short-term efficacy of YH-16 combined with GP regimen for advanced non-small cell lung cancer. Zhongliu Fangzhi Yanjiu, 38(2), 199-201.

Chen, Y. X., Cheng, H. N., \& Chen, L. (2010). Efficacy of endostar combined with vinorelbine and cisplatin in treatment of advanced non-small-cell Lung cancer. Hainan Medical Journal, 21(18), 20-22.

Eisenhauer, E. A., Therasse, P., Bogaerts, J., Schwartz, L. H., Sargent, D., Ford, R., Dancey, J., Arbuck, S., Gwyther, S., Mooney, M., Rubinstein, L., Shankar, L., Dodd, L., Kaplan, R., Lacombe, D., \& Verweij, J. (2009). New response evaluation criteria in solid tumours: revised RECIST guideline (version 1.1). European Journal of Cancer, 45(2), 228-247. http://dx.doi.org/10.1016/j.ejca.2008.10.026.

Fang, L. (2017). Clinical observation on efficacy of recombinant human endostatin combined with chemotherapy for advanced non-small cell lung cancer. Journal of Medical Forum, 38(8), 49-50.

Ferry, D., Billingham, L., Jarrett, H., Dunlop, D., Woll, P. J., Nicolson, M., Shah, R., Thompson, J., Spicer, J., Muthukumar, D., Skailes, G., Leonard, P., Chetiyawardana, A. D., Wells, P., Lewanski, C., Crosse, B., Hill, M., Gaunt, P., \& O’Byrne, K. (2017). Carboplatin versus two doses of cisplatin in combination with gemcitabine in the treatment of advanced non-small-cell lung cancer: results from a British Thoracic Oncology Group randomised phase III trial. European Journal of Cancer, 83, 302-312. http://dx.doi.org/10.1016/j.ejca.2017.05.037.

Fu, H., Yuan, C. P., \& Xiao, C. J. (2015). Short term efficacy of Endostar combined with GP regimen in the treatment of advanced non-small cell lung cancer. Journal of Taishan Medical College, 36(12), 1367-1368.

Fu, Y., Tang, H., Huang, Y., Song, N., \& Luo, Y. (2009). Unraveling the mysteries of endostatin. IUBMB Life, 61(6), 613-626. http://dx.doi. org/10.1002/iub.215. PMid:19472178. 
Ge, W., Cao, D. D., Wang, H. M., Jie, F. F., Zheng, Y. F., \& Chen, Y. (2011). Endostar combined with chemotherapy versus chemotherapy alone for advanced NSCLCs: a meta-analysis. Asian Pacific Journal of Cancer Prevention, 12(11), 2901-2907. PMid:22393961.

Gu, Y., Lu, H. Y., \& Jiang, A. G. (2010). Clinical study of recombinant human endostatin combined with GP regimen for advanced non-small cell lung cancer. Journal of Clinical Medicine in Practice, 14(9), 86-87.

Guo, H. B. (2010). Efficacy of endostar combined with chemotherapy in the treatment of advanced non-small cell lung cancer. Chinese and Foreign Health Digest, 7(33), 120.

Hanna, G. G., Siva, S., Plumridge, N., Solomon, B., \& Ball, D. L. (2014). Preoperative chemotherapy for non-small-cell lung cancer. Lancet, 384(9939), 232-233. http://dx.doi.org/10.1016/S0140-6736(14)612083. PMid:25042230.

Haynes, B. R., Sackett, D. L., Guyatt, G. H., \& Tugwell, P. (2006). Clinical epidemiology: how to do clinical practice research. Philadelphia: Lippincott Williams \& Wilkins.

He, R. (2012). Analysis on efficacy of endostar combined with cisplatin chemotherapy in treatment of senile advanced non -small cell lung cancer. Practical Preventive Medicine, 19(8), 1230-1232.

Holmsten, K., Jensen, N. V., Mouritsen, L. S., Jonsson, E., Mellnert, C., Agerbæk, M., Nilsson, C., Moe, M., Carus, A., Öfverholm, E., Lahdenperä, O., Brandberg, Y., Johansson, H., Hellström, M., Maase, H. V., Pappot, H., \& Ullén, A. (2020). Vinflunine/gemcitabine versus carboplatin/gemcitabine as first-line treatment in cisplatin-ineligible patients with advanced urothelial carcinoma: a randomised phase II trial (VINGEM). European Journal of Cancer, 127, 173-182. http:// dx.doi.org/10.1016/j.ejca.2019.08.033.

Jia, X. Q., Sun, Q. Y., \& Wen, Z. P. (2017). Clinical observation of recombinant human endostatin combined with gemcitabine and cisplatin therapy in advanced non-small cell lung cancer. Inner Mongolia Medical Journal, 49(1), 29-32.

Khan, M. R., Alammari, A. M., Aqel, A., \& Azam, M. (2020). Trace analysis of environmental endocrine disrupting contaminant bisphenol A in canned, glass and polyethylene terephthalate plastic carbonated beverages of diverse flavors and origin. Food Science and Technology. In press. http://dx.doi.org/10.1590/fst.03420.

Li, L. H., Fu, Y. M., \& Jin, Z. (2016). Investigation of gemcitabine combined with endostatin in the treatment of advanced non-small cell lung cancer. Jiangxi Medical Journal, 51(12), 1412-1414.

Liu, J. W., Geng, L., \& Liu, Z. W. (2012). Efficacy of endo combined with GP chemotherapy in the treatment of non-small cell lung cancer. Monthly Psychiatrist, 17, 121-122.

Liu, T. (2015). Clinical efficacy of GP regimen combined with Endostar in the treatment of advanced non-small cell lung cancer. China Practical Medicine, 10(2), 43-44.

Luan, W. Q. (2012). Relationship between circulating endothelial progenitor cells and Endostar in non-small cell lung cancer. Zhengzhou: Zhengzhou Univerisity.

Mao, Y., Yang, D., He, J., \& Krasna, M. J. (2016). Epidemiology of Lung Cancer. Surgical Oncology Clinics of North America, 25(3), 439-445. http://dx.doi.org/10.1016/j.soc.2016.02.001. PMid:27261907.

Moschos, S. J., Odoux, C., Land, S. R., Agarwala, S., Friedland, D., Volker, K. M., Sidor, C., Wong, M., \& Kirkwood, J. M. (2007). Endostatin plus interferon-alpha2b therapy for metastatic melanoma: a novel combination of antiangiogenic and immunomodulatory agents. Melanoma Research, 17(3), 193-200. http://dx.doi.org/10.1097/ CMR.0b013e3281ad91a3. PMid:17505265.

Navarro-Peraza, R. S., Osuna-Ruiz, I., Lugo-Sánchez, M. E., PachecoAguilar, R., Ramírez-Suárez, J. C., Burgos-Hernández, A., Martínez-
Montaño, E., \& Salazar-Leyva, J. A. (2020). Structural and biological properties of protein hydrolysates from seafood by-products: a review focused on fishery effluents. Food Science and Technology, 40(1, Suppl. 1), 1-5. http://dx.doi.org/10.1590/fst.24719.

O’Reilly, M. S., Boehm, T., Shing, Y., Fukai, N., Vasios, G., Lane, W. S., Flynn, E., Birkhead, J. R., Olsen, B. R., \& Folkman, J. (1997). Endostatin: an endogenous inhibitor of angiogenesis and tumor growth. Cell, 88(2), 277-285. http://dx.doi.org/10.1016/S00928674(00)81848-6. PMid:9008168.

Ruan, M., \& Sun, L. Y. (2011). Observation on the efficacy of recombinant human endostatin combined with GP regimen in the treatment of advanced non-small cell lung cancer. Chinese and Foreign Health Digest, 8(30), 54-55.

Sathiakumar, N., Delzell, E., Morrisey, M. A., Falkson, C., Yong, M., Chia, V., Blackburn, J., Arora, T., \& Kilgore, M. L. (2013). Mortality following bone metastasis and skeletal-related events among patients 65 years and above with lung cancer: a population-based analysis of U.S. Medicare beneficiaries, 1999-2006. Lung India, 30(1), 2026. http://dx.doi.org/10.4103/0970-2113.106127. PMid:23661912.

Scagliotti, G. V., De Marinis, F., Rinaldi, M., Crinò, L., Gridelli, C., Ricci, S., Matano, E., Boni, C., Marangolo, M., Failla, G., Altavilla, G., Adamo, V., Ceribelli, A., Clerici, M., Di Costanzo, F., Frontini, L., \& Tonato, M. (2002). Phase III randomized trial comparing three platinum-based doublets in advanced non-small-cell lung cancer. Journal of Clinical Oncology, 20(21), 4285-4291. http://dx.doi. org/10.1200/JCO.2002.02.068. PMid:12409326.

Shi, H., Huang, Y., Zhou, H., Song, X., Yuan, S., Fu, Y., \& Luo, Y. (2007). Nucleolin is a receptor that mediates antiangiogenic and antitumor activity of endostatin. Blood, 110(8), 2899-2906. http://dx.doi. org/10.1182/blood-2007-01-064428. PMid:17615292.

Siegel, R. L., Miller, K. D., \& Jemal, A. (2016). Cancer statistics, 2016. CA: a Cancer Journal for Clinicians, 66(1), 7-30. http://dx.doi. org/10.3322/caac.21332. PMid:26742998.

Song, W. C., Bao, Y., \& Qian, J. (2018). Study on clinical efficacy of endostar combined with gemcitabine and cisplatin in the treatment of advanced lung squamous cell carcinoma and effect on quality of life. The Practical Journal of Cancer, 33(1), 59-62.

Stukov, A. N., Bespalov, V. G., Alexandrov, V. A., Semenov, A. L., Kireeva, G. S., Semiglazova, T. Y., Filatova, L. V., \& Baranenko, D. A. (2020). Efficacy of gemcitabine on intracranial erlich tumor and its determinants. Drug Research, 70(2-3), 86-90. http://dx.doi. org/10.1055/a-0824-6325.

Tan, Y., Zhang, T., Peng, J. J., \& Zhao, Y. (2013). Short-term Efficacy and Safety of Recombinant Human Endostatin Combined with GP Regimen in the Treatment of Advanced Non-small Cell Lung Cancer. China Pharmacy, 24(36), 3416-3418.

Tao, H., Xiaokun, Y., Jianlei, J., Qinghai, W., Hongyang, W., \& Zhen, D. (2019). Inhibitory effects of tanshinone IIA from Salvia miltiorrhiza Bge on human bladder cancer BIU-87 cells and xenograft in nude mice. Food Science and Technology, 40(1)

Wang, D., \& Lippard, S. J. (2005). Cellular processing of platinum anticancer drugs. Nature Reviews. Drug Discovery, 4(4), 307-320. http://dx.doi.org/10.1038/nrd1691. PMid:15789122.

Wang, F. (2011). Clinical study of endostar combined with GP regimen in the treatment of advanced non-small cell lung cancer. Medicina Infantil, 24(11), 118-119.

Wang, Z. F. (2018). Effects of endo combined with first-line GP chemotherapy on survival time and quality of life in patients with advanced lung squamous cell carcinoma. Journal of Medical Theory and Practice, 31(2), 210-211. 
Wei, Q. H., Ding, H. Z., \& Tao, Y. J. (2010). Observation of treating advanced non- small cell lung cancer with recombinant human endostatin combined with GP. Journal of Clinical Medicine in Practice, 14(1), 36-38.

Wu, Y. L., Lu, S., Cheng, Y., Zhou, C., Wang, M., Qin, S., Lu, Y., Zhang, Y., Zhu, Y., Song, X., Wang, X., Barraclough, H., Zhang, X., Chi, H., \& Orlando, M. (2014). Efficacy and safety of pemetrexed/ cisplatin versus gemcitabine/cisplatin as first-line treatment in Chinese patients with advanced nonsquamous non-small cell lung cancer. Lung Cancer, 85(3), 401-407. http://dx.doi.org/10.1016/j. lungcan.2014.07.007. PMid:25082564.

Xie, Y. R., \& Huang, J. J. (2009). Clinical study of Endostar combined GP regimen in the treatment of advanced non-small cell lung cancer. Chinese Journal of Gerontolog, 29(16), 2035-2037.

$\mathrm{Xu}, \mathrm{J} .(2010)$. Evaluation of clinical efficacy of recombinant human endostatin combined with interventional therapy in non-small cell lung cancer. Guangzhou: China Southern Medical University.

Xu, L., \& Wu, L. (2017). Clinical observation of recombinant human endostatin combined with GP chemotherapy for advanced nonsmall cell lung cancer. Chinese Journal of Clinical Rational Drug Use, 10(13), 91-92.

Xu, X., Mao, W., Chen, Q., Zhuang, Q., Wang, L., Dai, J., Wang, H., \& Huang, Z. (2014). Endostar, a modified recombinant human endostatin, suppresses angiogenesis through inhibition of Wnt $/ \beta$ catenin signaling pathway. PLoS One, 9(9), e107463. http://dx.doi. org/10.1371/journal.pone.0107463. PMid:25232946.

Yin, F., Wu, L., \& He, W. (2012). Clinical application of recombinant human endostatin combined with GP protocol in advanced non- small cell lung cancer. Journal of Clinical Pulmonary Medicine, 17(11), 2098-2099.

Zhang, Y. Y. (2014). Clinical study of first-line treatment of advanced human squamous cell carcinoma with recombinant human endostatin (endostar) combined with chemotherapy (GP protocol). Hangzhou: Zhejiang University.

Zheng, Q. P., Luo, Z. X., \& Li, J. (2011). Clinical observation of endostatin combined with GP regimen in the treatment of stage IV non-small cell lung cancer. Guangxi Medical Journal, 33(5), 564-565.

Zhong, L., \& Chen, F. C. (2018). Efficacy and safety of Endostar combined with chemotherapy in the treatment of advanced non-small cell lung cancer. Chinese Manipulation \& Rehabilitation Medicine, 9(2), 66-67.

Zhong, W. Z., Chen, K. N., Chen, C., Gu, C. D., Wang, J., Yang, X. N., Mao, W. M., Wang, Q., Qiao, G. B., Cheng, Y., Xu, L., Wang, C. L., Chen, M. W., Kang, X., Yan, W., Yan, H. H., Liao, R. Q., Yang, J. J., Zhang, X. C., Zhou, Q., \& Wu, Y. L. (2019). Erlotinib Versus Gemcitabine Plus Cisplatin as Neoadjuvant Treatment of Stage IIIA-N2 EGFRMutant Non-Small-Cell Lung Cancer (EMERGING-CTONG 1103): A Randomized Phase II Study. Journal of Clinical Oncology, 37(25), 2235-2245. http://dx.doi.org/10.1200/JCO.19.00075. PMid:31194613.

Zhou, X., Zhang, Z., \& Liang, X. (2020). Regulatory network analysis to reveal important miRNAs and genes in non-small cell lung cancer. Cell Journal, 21(4), 459-466. PMid:31376328.

Zhu, Y. S., Li, Y. L., Ju, J. Q., Du, F., Zang, Y. P., Wang, X. B., \& Sheng, J. (2016). Oral chinese herbal medicine for treatment of dilated cardiomyopathy: a systematic review and meta-analysis. EvidenceBased Complementary and Alternative Medicine, 2016, 1819794. http://dx.doi.org/10.1155/2016/1819794. 